\title{
Perfilhamento e Algumas Características Morfológicas do Capim-Elefante cv. Roxo sob Quatro Alturas de Corte em Duas Épocas do Ano ${ }^{1}$
}

\author{
Estácio Alves dos Santos ${ }^{2}$, Divan Soares da Silva ${ }^{3}$, José Leite de Queiroz Filho ${ }^{3}$
}

\begin{abstract}
RESUMO - O objetivo deste trabalho foi verificar o efeito dos cortes efetuados a $0,15,30$ e $45 \mathrm{~cm}$ sobre algumas características morfofisiológicas do Pennisetum purpureum, Schum. cv. Roxo nas épocas seca e chuvosa no Brejo Paraibano. As amostras foram obtidas de uma área útil de $8,4 \mathrm{~m}^{2}$ de cada parcela. Após o corte de uniformização, efetuaram-se dois cortes no período seco, em intervalos de 90 dias, e três no período chuvoso, em intervalos de 60 dias. Foram avaliados os seguintes parâmetros: perfilhamento, altura das plantas, porcentagens de folhas e colmos e relação folha/colmo (RF/C). Aos 25 dias após cada corte, foram feitas as contagens dos perfilhos existentes nas parcelas. De cada parcela tomou-se uma amostra de 3 a 5 perfilhos, seca em estufa, e separaram-se as frações de folhas e colmos. Houve interação dos fatores (altura x época do corte) quanto ao número de perfilhos por $\mathrm{m}^{2}$ e à RF/C. No período chuvoso, houve mais perfilhos basais que no período seco, e o número de perfilhos aéreo foi superior em todos os cortes acima do nível do solo. A RF/C foi superior na época chuvosa nas alturas de 30 e $45 \mathrm{~cm}$ do solo. Cortes mais altos apresentaram maior proporção de folhas e menor proporção de colmos. Os percentuais de folhas na época chuvosa foram maiores que os da época seca.
\end{abstract}

Palavras-chave: Altura de planta, Pennisetum purpureum, relação folha/colmo

\section{Tillering and Some Morphologic Characteristics of Elephant Grass var. Roxo, Cut at Four Heights in Two Periods of the Year}

\begin{abstract}
This work was carried out to evaluate the effect of cutting at 0,15,30 and $45 \mathrm{~cm}$ height, on some morphological and physiological characteristics of the Pennisetum purpureum, Schum., var. Roxo in dry and rainy seasons in the Paraiba swamp region. The samples were obtained from a useful area of $8,4 \mathrm{~m}^{2}$ from each parcel. After the uniformity cut, two cuts in dry season with 90 days interval and three cuts in the rainy season with 60 days interval were made. The number of tillers for $\mathrm{m}^{2}$, plants heights, leaves and stems percentage (dry matter basis) and the leaves/stem ratio (L/SR) were evaluated. At the $25^{\text {th }}$ day, the counting, after each cut, of the existent tillers in the plots. A sample of 3 or 5 tillers was taken from each parcel and they were dehydrated in air forced stove and the separation of leaves and stems fractions were done. There was interaction of the factors (cutting height vs. seasons) for number of tillers by $\mathrm{m}^{2}$ and L/SR. In the rainy season there was more basal tillering than in the dry period; and the number of aerial tillers was higher in all cutting made above the ground. The L/SR increased in rainy season in the 30 and $45 \mathrm{~cm}$ cutting height. The higher cuts presented larger proportion of leaves and smaller proportion of stems. The leaves percentages in rainy season were higher than those in dry season.
\end{abstract}

Key Words: leaf/stem ratio, Pennisetum purpureum, plant height

\section{Introdução}

A periodicidade das chuvas no Nordeste do Brasil constitui-se em um fator limitante para a forragicultura, tanto para as espécies exóticas como nativas, todavia, além da adaptação edafo-climática das espécies, o manejo inadequado pode impedir melhor aproveitamento de forrageiras com alto potencial produtivo.

O capim-elefante (Pennisetum purpureum, Schum.) possui boa adaptação climática e tem sido utilizado em larga escala por inúmeros produtores, tanto picado no cocho, como em regime de pastejo. Apresenta crescimento contínuo com o avançar da idade, chegando a produzir plantas com mais de 3 metros de altura. Quando usado em pastejo, o seu hábito de crescimento pode limitar sua utilização, devido ao rápido alongamento e amadurecimento do caule, chegando muitas vezes a alturas fora do alcance dos animais (VEIGA, 1994). Segundo esse autor, alguns dos pontos que explicam o êxito do manejo dessa espécie seriam a manutenção do maior número possível de pontos de crescimento e o acúmulo de forragem nos limites de alcance dos animais, garantindo que o manejo não comprometa a persistência da pastagem.

Em virtude de o capim-elefante ser utilizado para corte na maioria das vezes, alguns pesquisadores

\footnotetext{
1 Parte da Dissertação de Mestrado do primeiro autor. Trabalho financiado pela CAPES.

2 Pós-Graduando em Produção Animal, UNESP - Jaboticabal, SP - Rod. Paulo D. Castellane, Km 5, CEP 14870-000.E.mail: estacio@fcav.unesp.br

3 Professor do DZ/CCA/UFPB, Campus III, Areia-PB. CEP 58.397-000.
} 
divergem nas recomendações quanto à altura do corte a ser adotada na capineira. GOMIDE (1994) recomenda corte manual ou mecanicamente com 20$30 \mathrm{~cm}$ de altura do solo. Segundo MOZZER (1993), a melhor altura do corte sempre será rente ao solo, tendo em vista que o corte baixo é responsável pelo crescimento mais vigoroso das plantas. Cortes altos deixam muito resíduo, dificultam os cortes posteriores; além disso, as gemas axilares do resíduo apresentam intensas brotações, porém muito fracas. Apesar disso, WERNER et al. (1972) encontraram melhores resultados utilizando cortes mais altos $(60-70 \mathrm{~cm})$.

A idade da planta para o corte é um fator que pode interferir na altura da planta, no vigor do rebrote (ANDRADE e GOMIDE, 1971) e número de perfilhos (VIANA et al., 1979). Trabalhando com capimelefante, CANTO e TEIXEIRA (1972) observaram que plantas da cultivar Porto Rico-534 cortadas aos 58 e 90 dias apresentaram alturas de 1,00 e 1,50 m, respectivamente.

Não existe um consenso entre pesquisadores quanto aos efeitos do desfolhamento sobre o surgimento de perfilhos em forrageiras durante o seu desenvolvimento vegetativo. DETLING et al. (1980) afirmaram que o desfolhamento pode diminuir a atividade de perfilhamento; GRANT et al. (1983) sugerem que o desfolhamento pode aumentar o número de perfilhos, enquanto DETLING e PAINTER (1983) não observaram influência. Sabe-se, no entanto, que algumas gramíneas têm adaptações morfológicas e fisiológicas que permitem suportar repetidas desfolhações (MATCHES, 1992); daí o rebrote é dependente da ativação das gemas basais e da habilidade da planta para mobilizar carboidratos das diversas partes para os demais órgãos (CALDWEL et al. 1991). AGUILLAR-CHAVARIA (1985) notou que em capim-elefante o número de perfilhos por $\mathrm{m}^{2}$ é inversamente proporcional à altura das plantas.

Conforme WARD e BLASER (1961), o perfilhamento das gramíneas forrageiras seria a característica mais importante para o aumento da produtividade destas plantas, mas que pode ser influenciado pelo sistema de manejo da pastagem. FAVORETTO (1993) afirmou que, de acordo com a severidade de corte, o estádio de crescimento e o genótipo das plantas, a remoção do ápice ou de todo o caule pode promover ou inibir o seu perfilhamento. Segundo JACQUES (1994), o maior número de perfilhos vegetativos significa maior número de folhas e, consequientemente, maior número de gemas para desenvolvimento de perfilhos axilares.
HILLESHEIM e CORSI (1190) observaram que a predominância de perfilhos basais produz plantas muito altas e provavelmente dificulta o consumo no pastejo direto no verão. Os mesmos autores verificaram que o perfilhamento basal tende a promover maior perda de forragem no pastejo direto de capim-elefante, devendo-se, portanto, promover mais perfilhamento lateral e rápido crescimento para atingir alta disponibilidade de forragem e manejá-la sob forte pressão de pastejo. A necessidade de maior surgimento de perfilhos aéreos é também defendida por JACQUES (1994), quando afirma que em cortes mais altos $(50-60 \mathrm{~cm})$ deixa-se maior número de gemas axilares responsáveis pelo rebrote e reserva da planta, e que algumas folhas remanescentes são importantes na interceptação de luz, auxiliando na velocidade do rebrote.

Segundo MOZZER (1993), as brotações dos perfilhos aéreos a partir de gemas axilares correspondem a 70-80\% do número total de perfilhos e são responsáveis por apenas cerca de $20 \%$ da produção de massa verde da capineira, enquanto os 20 ou $30 \%$ dos perfilhos basais são responsáveis por aproximadamente $80 \%$ da produção total de massa verde. PEDREIRA e BOIN (1969) observaram que houve redução no número de perfilhos por área, do $42^{\circ}$ para o $63^{\circ}$ dia de idade; esta redução se dá devido à competição dos perfilhos por luminosidade. Assim, os perfilhos originados da base do colmo geralmente são mais altos que os perfilhos aéreos.

Maior frequência de corte em uma capineira tem influência no crescimento do sistema radicular da forrageira. Segundo YOUNGNER (1972), menores intervalos de corte refletem em menor peso de raízes, provocando diminuição no número de folhas e no perfilhamento das plantas, e consequiente enfraquecimento da capineira. Para BOTREL et al. (1994), alta produtividade tende a diminuir a relação folha/ colmo; o fato é que clones mais produtivos de capimelefante tendem a apresentar maior proporção de caules. Entre as cultivares de capim-elefante estudadas por QUEIROZ FILHO et al. (1995), a cultivar Roxo apresentou melhor relação lâmina/colmo aos 60 dias, com valores em torno de 1,43, e XAVIER et al. (1995) obteve 1,66 .

O potencial de perfilhamento em uma forrageira influencia a produção, a qualidade e a persistência das espécies perenes; por isso, HILLESHEIM e CORSI (1990) propuseram mudanças no manejo que venham promover redução da altura do meristema apical, favorecendo o perfilhamento lateral, para melhoria da estrutura da gramínea sob pastejo, diminuindo, por 
conseguinte, as perdas de forragem. Segundo esses autores, o estímulo à formação de perfilhos axilares em detrimento do perfilhamento basal resulta em vantagens, devido à menor tendência de elevação dos meristemas apicais, maior proporção de folhas e maior densidade de matéria seca por centímetro de altura da planta, quando comparados com os perfilhos basais.

O objetivo do presente trabalho foi determinar a influência da altura do corte sobre alguns parâmetros morfofisiológicos do capim-elefante nas épocas do ano de maior e menor precipitação no Brejo Paraibano.

\section{Material e Métodos}

O experimento foi desenvolvido na área de forragicultura do Departamento de Zootecnia do CCA-UFPB, Campus III, Areia-PB. O clima é do tipo AS quente e úmido, com chuvas de outonoinverno, e pluviosidiade média em torno de $1.400 \mathrm{~mm}$ anuais. A temperatura média anual varia entre 23 e $24^{\circ} \mathrm{C}$ e o solo é do tipo Podzólico Vermelho-Amarelo (BRASIL, 1973), com textura arenosa.

A região do Brejo Paraibano consiste de uma microregião geográfica com características climáticas peculiares, constituindo-se em uma área de microclima, o que acentua a relevância à observação dos dados meteorológicos; além disso, a distribuição pluviométrica durante o intervalo no qual se conduziu o experimento tornou este um período atípico, com chuvas distribuídas durante todo o ano, mesmo em período de típica estiagem (SANTOS, 2001a).

O plantio foi feito em parcelas medindo $15 \mathrm{~m}^{2}$, em covas com espaçamento de $70 \times 80 \mathrm{~cm}$, utilizando segmentos de colmo medindo cerca de $30 \mathrm{~cm} \mathrm{e}$ contendo três gemas. Por ocasião do plantio, foram aplicados em cobertura $30 \mathrm{~kg} / \mathrm{ha}$ de $\mathrm{P}_{2} \mathrm{O}_{5}, 20 \mathrm{~kg} / \mathrm{ha}$ de $\mathrm{K}_{2} \mathrm{O}$. Dois anos depois, em julho de 1996 , foi dado um corte rente ao solo para uniformização da capineira e feita a correção do $\mathrm{pH}$ do solo com aplicação de 2,8 t/ha de calcário. Quatro semanas após fez-se a adubação em cobertura aplicando $30 \mathrm{~kg}$ de $\mathrm{P}_{2} \mathrm{O}_{5}$, $20 \mathrm{~kg}$ de $\mathrm{K}_{2} \mathrm{O}$ e $50 \mathrm{~kg}$ de $\mathrm{N}$ por hectare na forma de superfosfato triplo, cloreto de potássio e sulfato de amônia, respectivamente.

Em 09/96 fez-se um corte de uniformização das parcelas nas alturas de $0,15,30$ e $45 \mathrm{~cm}$, iniciandose então o período experimental. Após o corte de uniformização, foi feita a aplicação de $50 \mathrm{~kg} / \mathrm{ha}$ de N pelo mesmo sistema. As aplicações de adubos seguiram recomendações feitas com base em análise do solo (SANTOS, 2001a).
Os cortes no capim foram efetuados manualmente e, para efeito de amostragem, foi considerada área útil de $8,4 \mathrm{~m}^{2}$ por parcela. Além do corte para uniformização das parcelas, foram feitos cinco cortes no intervalo de um ano para coleta de dados, sendo dois cortes em época de menor precipitação (julho a dezembro) a cada 90 dias e três cortes na época de maior precipitação (janeiro a junho), a cada 60 dias. Foi estudado o efeito das alturas dos cortes $(0,15,30$ e $45 \mathrm{~cm})$ e das épocas do ano (seca e chuvosa) sobre altura das plantas, números de perfilhos (basais e aéreos) e porcentagens de folhas e colmos.

As alturas das plantas foram medidas utilizando uma régua graduada de aproximadamente três metros, fazendo-se quatro leituras aleatórias em cada parcela e considerando a curvatura média da última folha.

Ao serem cortadas as plantas, foram amostrados 3 a 5 perfilhos inteiros por parcela, cortados em pedaços de $3 \mathrm{a} 4 \mathrm{~cm}$, pesados e colocados em estufa de ventilação forçada a $60^{\circ} \mathrm{C}$ durante 72 horas; após este tempo estas amostras foram pesadas e, em seguida, fez-se a separação das frações de colmos e folhas (lâmina + bainha).

A contagem dos perfilhos foi realizada no $25^{\circ}$ dia após cada corte, utilizando um quadrado de PVC medindo 1 metro de lado, o qual era lançado aleatoriamente sobre a área útil em cada parcela e se fazia a contagem dos perfilhos basilares e axilares contidos na área do quadrado.

$\mathrm{O}$ delineamento experimental foi o de blocos completos casualizados, num esquema fatorial $4 \times 2$; sendo quatro alturas de corte $(0,15,30$ e $45 \mathrm{~cm})$, duas épocas (seca e chuvas) e quatro repetições, conforme modelo matemático a seguir:

$$
\mathrm{Y}_{\mathrm{ijk}}=\mu+\alpha_{\mathrm{i}}+\mathrm{E}_{\mathrm{j}}+\beta \mathrm{k}+(\alpha \mathrm{E})_{\mathrm{ij}}+\mathrm{e}_{\mathrm{ijk}}
$$

em que $Y_{\mathrm{ijk}}$ é o valor relativo à parcela que recebeu o corte na altura i na época $\mathrm{j}$ e no bloco $\mathrm{k} ; \mu$, a média geral; $\alpha_{i}$, o efeito da i-ésima altura de corte; $E_{j}$, o efeito da j-ésima época; $\beta_{k}$, o efeito do k-ésimo bloco; $\alpha x E$, efeito da interação altura $\mathrm{x}$ época de corte; $\mathrm{e}_{\mathrm{ijk}}$, o erro aleatório associado a cada observação.

A análise de variância foi realizada pelo GLM Procedures (SAS, 1993) e as médias obtidas foram comparadas pelo teste Tukey a 5\% de significância.

\section{Resultados e Discussão}

\section{Alturas de plantas e densidade de perfilhos}

As alturas das plantas e o número de perfilhos por metro quadrado estão apresentados na Tabela 1 . Para o parâmetro de altura das plantas não foi 
SANTOS et al.

Tabela 1 - Médias das alturas das plantas, número de perfilhos basais, perfilhos aéreos e o total de perfilhos por $\mathrm{m}^{2}$ no capimelefante cv. Roxo, quando cortado em quatro alturas

Table 1 - Averages of plants height, basal tiller numbers, aerial tiller number, and total of tillers per $m^{2}$ of the elephant grass var. Roxo as cut in four heights

\begin{tabular}{|c|c|c|c|c|c|}
\hline \multirow[t]{2}{*}{$\begin{array}{l}\text { Altura do corte }(\mathrm{cm}) \\
\text { Cutting height }\end{array}$} & \multirow[t]{2}{*}{$\begin{array}{c}\text { Altura da planta }(\mathrm{m}) \\
\text { Plant height }\end{array}$} & \multicolumn{2}{|c|}{$\begin{array}{c}\text { Perfilho basal } \\
\text { Basal tiller }\end{array}$} & \multicolumn{2}{|c|}{$\begin{array}{c}\text { Perfilho aéreo } \\
\text { Aerial tiller }\end{array}$} \\
\hline & & $\begin{array}{c}\text { Seca }^{1} \\
\text { Dry season }\end{array}$ & $\begin{array}{c}\text { Chuvas }^{2} \\
\text { Rainy season }\end{array}$ & $\begin{array}{c}\text { Seca }^{1} \\
\text { Dry season }\end{array}$ & $\begin{array}{c}\text { Chuvas }^{2} \\
\text { Rainy season }\end{array}$ \\
\hline 0 & $1,53^{\mathrm{c}}$ & $57,5^{\mathrm{aB}}$ & $81,5^{\mathrm{aA}}$ & $1,5^{\mathrm{bA}}$ & $2,0^{\mathrm{cA}}$ \\
\hline 15 & $1,62^{b c}$ & $11,5^{\mathrm{bA}}$ & $14,2^{\mathrm{bA}}$ & $39,2^{\mathrm{aB}}$ & $74,7^{\mathrm{bA}}$ \\
\hline 30 & $1,66^{\mathrm{ab}}$ & $3,7^{\mathrm{bA}}$ & $7,7^{\mathrm{bA}}$ & $44,2^{\mathrm{aB}}$ & $95,5^{\mathrm{aA}}$ \\
\hline 45 & $1,72^{\mathrm{a}}$ & $4,7^{\mathrm{bA}}$ & $6,2^{\mathrm{bA}}$ & $51,2^{\mathrm{aB}}$ & $108,2^{\mathrm{aA}}$ \\
\hline Média & 1,63 & 19,4 & 27,4 & 34,1 & 70,1 \\
\hline Mean & & & & & \\
\hline $\mathrm{CV}(\%)$ & 4,66 & 26,11 & 31,19 & 10,44 & 18,15 \\
\hline
\end{tabular}

Médias seguidas de mesmas letras minúsculas nas colunas e maiúsculas nas linhas não diferem pelo teste Tukey (5\%).

Means followed by same small letter in the columns and capital letters in the row do not differ by Tukey test (5\%).

${ }^{1}$ Médias de dois cortes (Means of two cuttings).

2 Médias de três cortes (Mean of three cutting).

constatado efeito de interação entre as alturas dos corte e as épocas dos cortes, mas observou-se aumento linear $(\mathrm{P}<0,05)$ desta variável com a elevação das alturas dos cortes. Houve efeito $(\mathrm{P}<0,05)$ de interação para as demais variáveis, como mostra a Tabela 1. Para o número de perfilhos basais nos períodos de seca e chuvas, somente os cortes efetuados rentes ao solo apresentaram diferença $(\mathrm{P}<0,05)$, resultando em número maior de perfilhos por área; o número total de perfilhos por área na época chuvosa foi maior que na época seca para todas as alturas de corte.

Os cortes mais elevados resultaram em plantas mais altas; acredita-se que alguns perfilhos basais, quando foram cortados nas alturas de $45 \mathrm{~cm}$ do solo, não tiveram seus meristemas apicais eliminados, por isso alcançaram maiores alturas, e as plantas que tiveram decepadas suas gemas apicais já apresentavam número razoável de gemas axilares para a emissão de perfilhos aéreos.

Pelo número de perfilhos observados, verificou-se que a época chuvosa foi mais propícia ao perfilhamento do capim-elefante do que a época de seca (Tabela 1). No entanto, o efeito da época chuvosa não elevou significativamente a altura das plantas; resultados estes que estiveram de acordo com AGUILLARCHAVARIA (1985), o qual afirma que o número de perfilhos por metro quadrado é inversamente proporcional à altura das plantas, certamente devido à competição por luz. Neste experimento, o fato de as alturas das plantas terem sido maiores nos cortes efetuados na estiagem (Tabela 1) talvez tenha se dado em virtude das condições ambientais propícias de luminosidade, calor e umidade do solo naquele período (SANTOS 2001a).

As médias da Tabela 1 mostram que as alturas das plantas de capim-elefante roxo no presente trabalho estavam dentro da faixa ideal para corte (MOZZER, 1993). Estes resultados foram confirmado pelos resultados obtidos por DESCHAMPS (1997) com a mesma cultivar (1,51 m de altura aos 56 dias, e $2,13 \mathrm{~m}$ de altura aos 90 dias). Entretanto, ANDRADE e GOMIDE (1971) obtiveram maiores alturas de plantas ( 1,73 e 1,84 m cortadas aos 56 e 84 dias, respectivamente), ao trabalharem com a cultivar Taiwan A-146.

$\mathrm{O}$ fato de as alturas das plantas no período chuvoso terem se mostrado menores pode ter a ver com o intervalo de cortes, visto que cortes mais freqüentes resultam em plantas menores (YOUNGNER, 1972). Provavelmente uma das causas destes resultados seriam possíveis diminuições dos carboidratos de reserva armazenados pelas gramíneas na base do caule; sua escassez causa a redução do sistema radicular, limitando o desenvolvimento das plantas (RODRIGUES et al., 1987). Esta questão pode ser mais bem compreendida quando se considera que, na proporção em que se eleva a altura dos cortes, garante-se também maior quantidade de folhas restante nas plantas, para continuidade do processo fotossintético, utilizando bem menos as reservas existentes. Por isso, cortes com intervalo de 60 dias, embora com maior disponibilidade de água, diminuíram as médias das alturas das plantas (Tabela 1).

$\mathrm{Na}$ época das chuvas, a redução das alturas de 
28 Rev. bras. zootec.

corte tende a diminuir também o número total de perfilhos, talvez devido ao já mencionado acúmulo menor de reservas pelas plantas (GOMIDE et al., 1979) nesse período. Considerando que plantas altas dificultam o pastejo de bovinos, conforme comentaram HILLESHEIM e CORSI (1990), os resultados obtidos permitem inferir que, nas condições deste experimento, a utilização da capineira nos intervalos e condições ambientais do presente estudo teria que ser a mesma por meio do corte baixo, em razão tanto da altura das plantas quanto do percentual de colmos no resíduo.

O surgimento de maior número de perfilhos aéreos, resultantes de cortes mais elevados, obedece à ordem natural da existência de maior número de gemas axilares restantes nos caules residuais da capineira desbastada. Segundo MOZZER (1993), os perfilhos aéreos geralmente abrangem percentuais de 70 a $80 \%$ do total de perfilhos em uma capineira, mas participam em apenas com $20 \%$ aproximadamente da produção de matéria seca.

Percentuais de folhas, colmos e relação folha/colmo

$\mathrm{Na}$ Tabela 2 estão os percentuais médios das frações de folhas e colmos e a relação folha/colmo do capim-elefante em estudo. A análise de variância mostrou que não houve diferença significativa para a interação época $\mathrm{x}$ altura de corte para os percentuais de folhas e colmos, mas apenas para a relação folha/ colmo $(\mathrm{P}<0,05)$. O percentual de folhas variou significativamente $(\mathrm{P}<0,05)$, mostrando tendência linear crescente, e a fração de colmos variou negativamente, em função da elevação dos cortes.

Os cortes rentes ao solo apresentaram valores médios de $70,96 \%$ de folhas e $29,04 \%$ de colmos, enquanto os cortes com $45 \mathrm{~cm}$ de altura tiveram $76,64 \%$ de folhas e $23,36 \%$ de colmos; com a elevação dos cortes, no entanto, a diminuição do percentual de colmos melhora a relação folha/colmo. Estes resultados confirmam os achados por HILLESHEIN e CORSI (1990), os quais argumentam que a redução na altura do meristema apical melhoraria as condições de produção da capineira, porque os perfilhos laterais têm menor tendência para elevar o meristema apical; com isso, aumenta-se a proporção de folhas.

Maior relação folha/colmo foi observada no período das chuvas, com cortes efetuados mais altos $(30 \mathrm{e} 45 \mathrm{~cm}$ ). O aumento significativo da relação folha/colmo pode significar melhoria na qualidade da forragem na época chuvosa, entretanto, observou-se ter diminuído a produção de matéria seca por área em $25 \%$ em média (SANTOS et al., 2001b). A relação folha/colmo obtida foi superior aos resultados de MEIRELLES et al. (1997), que obtiveram relação $\mathrm{F} / \mathrm{C}$ de 0,89 no período chuvoso, e superior aos resultados de HARTHMANN et al. (1995), que encontraram 1,90 em cortes realizados com $50 \mathrm{~cm}$ de altura. Por outro lado, POLI et al. (1994) obtiveram até 4,66 com a cultivar Taiwan A-126; estes autores também constataram que no período seco a relação folha/colmo diminui significativamente em relação ao período chuvoso; resultados que concordam com os deste trabalho, nos cortes efetuados acima de $15 \mathrm{~cm}$.

Como mostra a Tabela 2, os cortes mais altos na época chuvosa resultaram em maior relação folha/ colmo, porque, à medida que se elevou a altura do corte, maior percentual de colmos foi deixado no

Tabela 2 - Percentuais de folhas e colmos e interação da relação folha/colmo (RF/C) do capim-elefante cv. Roxo em diferentes alturas de corte

Table 2 - Percentages of leaves and stem and leaf/stem ratio (L/SR) interaction of the elephant grass, var. Roxo in different cutting heights

\begin{tabular}{|c|c|c|c|c|}
\hline \multirow{2}{*}{$\begin{array}{l}\text { Altura do corte }(\mathrm{cm}) \\
\text { Cutting height }\end{array}$} & \multirow{2}{*}{$\begin{array}{c}\text { Folha }(\%) \\
\text { Leaf }(\%)\end{array}$} & \multirow{2}{*}{$\begin{array}{c}\text { Colmo }(\%) \\
\text { Stem }(\%)\end{array}$} & \multicolumn{2}{|c|}{$\mathrm{RF} / \mathrm{C}(L / S R)$} \\
\hline & & & $\begin{array}{c}\text { Seca }^{1} \\
\text { Dry season }\end{array}$ & $\begin{array}{c}\text { Chuvas }^{2} \\
\text { Rainy season }\end{array}$ \\
\hline 0 & $70,96^{\mathrm{c}}$ & $29,04^{\mathrm{a}}$ & $2,77^{\mathrm{b} \mathrm{A}}$ & $2,72^{\mathrm{bA}}$ \\
\hline 15 & $73,91^{\mathrm{bc}}$ & $26,09^{\mathrm{ab}}$ & $3,64^{\mathrm{a} A}$ & $3,39^{\mathrm{bA}}$ \\
\hline 30 & $78,66^{\mathrm{a}}$ & $21,34^{\mathrm{c}}$ & $3,17^{\mathrm{abB}}$ & $5,36^{\mathrm{aA}}$ \\
\hline 45 & $76,64^{\mathrm{ab}}$ & $23,36^{b c}$ & $3,04^{\mathrm{abB}}$ & $4,68^{\mathrm{aA}}$ \\
\hline Média & 75,04 & 24,96 & 3,16 & 4,04 \\
\hline \multicolumn{5}{|l|}{ Mean } \\
\hline $\mathrm{CV}(\%)$ & 4,09 & 12,42 & 9,32 & 13,59 \\
\hline
\end{tabular}

Médias seguidas de mesmas letras minúsculas nas colunas e maiúsculas nas linhas não diferem pelo teste Tukey (5\%).

Means followed by same small letter in the columns and capital letters in the row do not differ by Tukey test (5\%).

${ }^{1}$ Médias de dois cortes (Means of two cuttings).

2 Médias de três cortes (Mean of three cutting). 
campo. Por outro lado, a relação folha/colmo nos cortes mais baixos $(0$ e $15 \mathrm{~cm})$ não diferiu $(\mathrm{P}>0,05)$ de uma época para outra.

$\mathrm{Na}$ Tabela 3, nota-se que as características morfológicas do capim-elefante foram diferentes $(\mathrm{P}<0,05)$ nos dois períodos experimentais. Pode-se verificar que, com exceção da altura das plantas, a época chuvosa foi mais propícia a todas as demais variáveis, ou seja, no período em que as plantas tinham maior disponibilidade de água foi melhor o seu desempenho quanto ao perfilhamento, surgimento e permanência de folhas em menor intervalo de corte.

O maior percentual de folhas em relação ao de colmos na época chuvosa poderia estar relacionado com a umidade, associada a uma temperatura favorável à expansão da lâmina foliar, conforme argumentaram Ito e Inananga, citados por PASSOS (1994). Os valores referentes aos percentuais de folhas no período seco e chuvoso (Tabela 1) apontam resultados superiores para a fração de folhas no período de maior precipitação. Estes resultados certamente podem ser decorrentes de maior alongamento do caule durante o período mais seco, quando foram efetuados apenas

Tabela 3 - Médias observadas sobre alguns aspectos morfofisiológicos do capim-elefante cv Roxo no período experimental

Table 3 - Observed means on some morphophysiological aspects of the elephant grass var. Roxo in the experimental period

\begin{tabular}{lcc}
\hline $\begin{array}{l}\text { Variável } \\
\text { Variable }\end{array}$ & $\begin{array}{c}\text { Período } \\
\text { seco }\end{array}$ & $\begin{array}{c}\text { Período } \\
\text { chuvoso }\end{array}$ \\
\hline $\begin{array}{l}\text { Altura da planta }(\mathrm{m}) \\
\text { Plant height }\end{array}$ & $1,79^{\mathrm{A}}$ & $1,47^{\mathrm{B}}$ \\
$\begin{array}{l}\text { Perf. basal }\left(\mathrm{n}^{\circ} / \mathrm{m}^{2}\right) \\
\text { Basal tiller }\end{array}$ & $19,40^{\mathrm{B}}$ & $27,70^{\mathrm{A}}$ \\
$\begin{array}{l}\text { Perf. axilares aerial }\left(\mathrm{n}^{\circ} / \mathrm{m}^{2}\right) \\
\text { Axilary tiller } \\
\text { Total de perfilhos }\left(\mathrm{n}^{\circ} / \mathrm{m}^{2}\right)\end{array}$ & $34,10^{\mathrm{B}}$ & $70,10^{\mathrm{A}}$ \\
$\begin{array}{l}\text { Total } \text { of tiller } \\
\% \text { folha } \\
\text { \% leave }\end{array}$ & $52,90^{\mathrm{B}}$ & $97,40^{\mathrm{A}}$ \\
$\begin{array}{l}\text { \% colmo } \\
\% \text { of stem }\end{array}$ & $72,05^{\mathrm{B}}$ & $78,04^{\mathrm{A}}$ \\
$\begin{array}{l}\text { Rel. Folha/Colmo } \\
\text { Leaf/stem ratio }\end{array}$ & $27,95^{\mathrm{A}}$ & $21,96^{\mathrm{B}}$ \\
\hline
\end{tabular}

Médias, na linha, seguidas de mesmas letras não diferem pelo teste Tukey a $5 \%$.

Means, within a row followed by same letters did not differ by Tukey test (5\%).

1 Médias de dois cortes (Means of two cuts).

2 Médias de três cortes (Means of three cuts). dois cortes em intervalos de 90 dias e, ainda, provavelmente da redução da área foliar como mecanismo de defesa das plantas contra o estresse hídrico, face à incidência de luminosidade nesse período. A variação destes percentuais provocou a oscilação da relação folha/colmo.

\section{Conclusões}

Os cortes mais elevados resultaram em plantas mais altas independente da época e forneceram proporções maiores de folhas e maior número perfilhos aéreos.

A época mais chuvosa ofereceu melhores condições ao perfilhamento das plantas e melhorou a relação folha/colmo.

Os cortes efetuados no período de menor precipitação pluviométrica promoveram o menor acúmulo de folhas e as maiores proporções colmos na capineira do que no período chuvoso.

\section{Referências Bibliográficas}

AGUILLAR CHAVARIA, A.J. Avaliação da sobrevivência ao estresse hídrico e de outras características morfo-fisiológicos de sete clones de capim-elefante (Pennisetum purpureum, Schum.) em condições controladas. Recife, 1985. 189p. Dissertação (Mestrado em Produção Animal) - Universidade Federal Rural de Pernambuco, 1985.

ANDRADE, I.F., GOMIDE, J.A. 1971. Curva de crescimento e valor nutritivo de capim-elefante (Pennisetum purpureum, Schum.) Taiwan A-146. R. Ceres, (18):431-447.

BOTREL, M.A., ALVIM, J.M., MARTINS, C.E. 1994. Avaliação e seleção de cultivares de capim-elefante (Pennisetum purpureum, Schum.) para pastejo. R. Soc. Bras. Zootec., 23(5):755.

BRASIL. Departamento Nacional de Obras Contra a Seca. 1973. Relatório Anual. Recife: DNOCS. p.47-56.

CALDWELL, M. RICHARD, J.H., JOHNSON, D.A. et al. 1991. Coping with herbivore: photosynthetic capacity and resource allocation in two semiarid. Agrophyron bunchgrasses. Oecologia, 50:14-24.

CANTO, A.C., TEIXEIRA, L.B. 1972. Efeitos de intervalos entre cortes na produção do capim-elefante "Porto rico - 534. Manaus-Am: IEAAOc. Indicação de Pesquisa. 9p. (Informativo).

DESCHAMPS, F.C. Perfil fenológico de três ecotipos de capimelefante (Pennisetum purpureum Schum.). In: REUNIÃO ANUAL DA SOCIEDADE BRASILEIRA DE ZOOTECNIA, 34, 1997, Juiz de Fora. Anais... Juiz de Fora: SBZ, 1997. v.2, p.61-63.

DETLING, J.K., PAINTER, E.L. 1980. Defoliation response of western wheatgrass population with diverse histories of prairie dot grazing. L. Ecolog., 51:65-71.

DETLING J.K., DYER, M.I., PROCTOR-GREGG, C., WINN, D.T. 1980. Plant herbivore interactions examinations of potential effects bison saliva on regrowth of Boutiloua. Gracilis (HBK) L. Ecolog., 45:26-31.

FAVORETTO, V. Adaptações de plantas forrageiras ao pastejo. In: SIMPÓSIO SOBRE ECOSSISTEMAS DE PASTAGENS, 
30 Rev. bras. zootec.

2, 1993. Jaboticabal. Anais... Jaboticabal: FUNEP, 1993. p.1-17.

GOMIDE, J.A. 1994. Formação e utilização de capineira de capim-elefante. In: CARVALHO, M.M., ALVIM, M.J., XAVIER, D.F. et al. (Eds.) Capim-elefante, produção e utilização. Coronel Pacheco: EMBRAPA/CNPGL. p.81-116.

GOMIDE, J.A., OBEID, J.A., RODRIGUES, L.R.A. 1979. Fatores morfofisiológicos de rebrota do capim colonião (Panicum maximum). R. Soc. Bras. Zootec., 8:532-62.

GRANT, S.A., BARTHRAM, S., TORVELL, C. et al. 1983. Sward management tannin turnow and tiller populations density in continuously stoked lolium perene denominated swards. Grass and Forage Sci., 38:333-334.

HARTHMANN, D.E.L., JACQUES, A.V.A, TERMIGNO R.R. Avaliação agronômica de plantas de capim-elefante regeneradas in vitro. In: REUNIÃO ANUAL DA SOCIEDADE BRASILEIRA DEZOOTECNIA, 32, 1995, Brasília. Anais... Brasília: SBZ, 1995. p.26-28.

HILLESHEIN, A., CORSI, M. 1990. Capim-elefante sob pastejo: fatores que afetam as perdas e utilização da matéria seca. Pesq. Agrop. Bras., 25(9):1233-1246.

JACQUES, A.V.A. 1994. Caracteres morfofisiológicos e suas implicações com o manejo. In: CARVALHO, M.M., ALVIM, M.J., XAVIER, D.F. et al. (Eds.) Capim-elefante, produção e utilização. Coronel Pacheco: EMBRAPA/CNPGL. p.31-48.

MATCHES, A.G. 1992. Plant response to grazing a review. J. Prod. Agric., 5(1): 1-7.

MEIRELLES, P.R., PEREIRA, A.V., MOCHIUTTI, S. Avaliação e seleção de capim-elefante no Cerrado do Amapá. In: REUNIÃO ANUAL DA SOCIEDADE BRASILEIRA DE ZOOTECNIA, 34, Juiz de Fora, 1997. Anais... Juiz de Fora: SBZ, 1997. v.2, p.97-99.

MOZZER, O.L. 1993. Capim-elefante - Curso de Pecuária Leiteira. Coronel Pacheco: EMBRAPA/CNPGL. 2.ed. (Documentos n. 43).

PASSOS, L.P. Estado do conhecimento sobre a fisiologia do capim-elefante. In: SIMPÓSIO SOBRE CAPIM-ELEFANTE, 2, Coronel Pacheco, 1994. Anais... Coronel Pacheco: EMBRAPA, 1994. p.12-56.

PEDREIRA, J.V.S., BOIN, C. 1969. Estudo do crescimento do capim-elefante variedade Napier (Pennisetum purpureum, Schum.). Bol. Ind. Anim., (26):263-273,

POLI, C.H.E.C., JACQUES, A.V.A., CASTILHOS, Z.M.S et al. 1994. Caracterização morfológica de cinco cultivares de capim-elefante (Pennisetum purpureum, Schum.). R. Soc. Bras. Zootec., 23:205-210.
QUEIROZ FILHO, J.L., SILVA, D.S., SILVA, F.J.M. et al. Avaliação de cultivares de capim-elefante (Pennisetum purpureum, Schum.) no Brejo Paraibano. In: REUNIÃO ANUAL DA SOCIEDADE BRASILEIRA DE ZOOTECNIA, 32, Brasília, 1995. Anais... Brasília: SBZ, 1995. p.117-118.

RODRIGUES, L.R.A., MOTTE, G.O., VEIGA, J.B. et al. 1987. Effects of grazing management on leaf and total nonstructural carbohydrates of dwarf elephant grass. Pesq. Agrop. Bras., 22:195-201.

SAS - statistical analysis systems. User's guide: Stat, Version 6, 4.ed, v.1/2. Cary North Caroline: SAS Institute, 1993.

SANTOS, E.A., SILVA, D.S., QUEIROZ FILHO. J.L. 2001 a. Composição química do capim-elefante cv. Roxo cortado em diferentes alturas. Rev. bras. zootec., 30(1):18-23.

SANTOS, E.A., SILVA, D.S., QUEIROZ FILHO. J.L. 2001b. Aspectos produtivos do capim-elefante(Pennisetum purpureum, Schum.) cv. Roxo no Brejo Paraibano. Rev. bras. zootec., 30(1):31-36.

VEIGA, J.B. 1994. Utilização do capim-elefante sob pastejo. In: CARVALHO, M.M., ALVIM, M.J., XAVIER, D.F. et al. (Eds.) Capim-elefante, produção e utilização. Coronel Pacheco: EMBRAPA/CNPGL. p.165-93.

VIANA, J.O., ARAÚJO FILHO, A.J., GADELHA, A.J. 1979. Efeito residual dos intervalos de cortes em capim-elefante (Pennisetum purpureum, Schum.).Cienc. Agron., 9(1/2): 41-45,

WARD, V.Y., BLASER, R.E. 1961. Carbohydrates feed reserves and leaf. Crop Sci., 1:366-370.

WERNER, J.C., LIMA F.P., MARTINELLI, D., CINTRA, B. 1966. Estudos de três diferentes alturas de corte em capimelefante napier. Bol. Ind. Anim., 23(único):161-68.

XAVIER, D.F., BOTREL, M.A., DAHER, R.F. et al. 1995. Caracterização morfológica de algumas cultivares de capim-elefante. Coronel Pacheco: EMBRAPA/CNPGL. 24p. (Documentos 60).

YOUNGNER, V.B. 1972. Physiology of defoliation and regrowth. In: YOUNGNER, V.B., MICKELL, C.M. (Eds.) The biology and utilization of grasses. London: Academic Press. p.292-304.

Recebido em: $15 / 05 / 00$ Aceito em: 29/09/00 